\title{
Impact of a helmet law on two wheel motor vehicle crash mortality in a southern European urban area
}

\author{
Josep Ferrando, Antoni Plasència, Miquel Orós, Carme Borrell, Jess F Kraus
}

\begin{abstract}
Background-In Spain, a federal road safety law went into effect in the fall of 1992 extending to urban areas the unrestricted use of safety helmets by all two wheel motor vehicle occupants.

Objectives-To assess the effect of the law in reducing fatal motorcycle crash injuries; to estimate the number of lives saved; and to determine changes in the distribution of severity and anatomical location of injuries.
\end{abstract}

Methods-Pre-test/post-test design of all deaths of two wheel motor vehicle occupants from 1990-92 (pre-law period) and from 1993-95 (post-law period) detected by the Barcelona Forensic Institute and the city police department. Injuries were coded using the 1990 version of the abbreviated injury scale. Poisson regression methods were used to model trends in mortality ratios and to provide estimates of the number of lives saved.

Results-Between 1993 and 1995, 35 lives of two wheel motor vehicle occupants were spared, representing a decrease of $25 \%$ in the observed motorcycle crash mortality in the post-law period when compared with what would be expected if no such law had gone into effect. The proportion of deaths with severe head injuries was also reduced from $76 \%$ to $67 \%$ in the post-law period.

Conclusions-This study offers the first evaluation of a helmet law using combined forensic and police data in a large south European urban area where there is widespread use of motorcycles. Our results confirm the effectiveness of the helmet law, as measured by the reduction in the number of deaths and mortality ratios after the law implementation. The findings reinforce the public health benefits of mandatory non-restricted motorcycle and moped helmet use, even in urban areas with lower traffic speeds.

(Injury Prevention 2000;6:184-188)

Keywords: head injuries; helmets; motorcycles; helmet law
In the European Union, the burden of traffic injuries on premature death and disability has been consistently higher in southern countries than in northern countries. Among the former, Spain ranks third in mortality due to traffic injuries, with 171 deaths per million inhabitants. ${ }^{1}$ One feature of Spain crash deaths is that one out of every four injury cases is an occupant of a motorcycle or a moped. ${ }^{2}$ This contribution is even more salient in urban areas, where $46 \%$ of traffic injury cases involve two wheel motor vehicle occupants. ${ }^{2}$ In Barcelona, the second largest city in Spain, two wheel motor vehicle occupants have a sixfold increased risk of an injury compared with car occupants, with $45 \%$ of those attending an emergency department for a traffic injury being motorcycle or moped occupants. ${ }^{3}$ Moreover, three of every four of such cases are less than 30 years of age, and account for the largest share of disabilities resulting from traffic injuries ${ }^{4}$; this clearly underscores the importance of motorized two wheel vehicles in the traffic injury scenario.

Head injury is a very common, as well as severe, outcome among motorcyclists who crash and the motorcycle helmet has been the principal countermeasure for decreasing such injuries. $^{5-8}$ Many studies have concluded that helmets decrease the severity of injury and the likelihood of deaths, ${ }^{9-21}$ together with a reduction in health care costs. ${ }^{10121415171921-26} \mathrm{Re}-$ search has also shown the effectiveness of laws requiring the use of helmets by two wheel motor vehicle occupants for the reduction of fatalities and injuries in this user category. ${ }^{18} 22$ 26-29 Nevertheless, most of these studies have not looked specifically at the impact of helmet laws in urban environments, where crashes tend to involve lower speed impacts and, hence, result in injuries of potentially lower severity.

In Spain, a federal road safety law went into effect in the fall of 1992 extending to urban areas the unrestricted use of safety helmets by all two wheel motor vehicle users. In Barcelona, a previous study showed a beneficial effect of the helmet law, but the assessment was limited to one year after the law and was solely based on police data. ${ }^{30}$ 
Table 1 Mortality in two wheel vehicle users (Barcelona 1990-95)

\begin{tabular}{|c|c|c|}
\hline & $\begin{array}{l}\text { Pre-law } \\
(1990-92)\end{array}$ & $\begin{array}{l}\text { Post-law } \\
\text { (1993-95) }\end{array}$ \\
\hline \multicolumn{3}{|l|}{ Gender $(\%)^{\star}$} \\
\hline Male & $141(82.9)$ & $96(87.3)$ \\
\hline Female & $29(17.1)$ & $14(12.7)$ \\
\hline \multicolumn{3}{|l|}{ User type $(\%)^{\star}$} \\
\hline Driver & 145 (85.3) & $93(84.5)$ \\
\hline Passengers & $25(14.7)$ & $17(15.5)$ \\
\hline All & $170(100)$ & $110(100)$ \\
\hline Mean (SD) age & $25(12.4)$ & $25(8.2)$ \\
\hline
\end{tabular}

${ }^{\star}$ Not significant.

The purpose of the present study was: (1) to assess the impact of the road safety law in reducing fatal motorcycle crash injuries in an urban area where there is a widespread use of two wheel motor vehicles; (2) to estimate the number of lives saved by the use of motorcycle helmets after the implementation of the law; and (3) to determine changes in the distribution of severity and anatomical location of injuries in fatal cases before and after the law.

\section{Methods}

The study use a pre-test/post-test design ${ }^{31}$ to evaluate the effect of the law by comparing data on traffic related deaths among two wheel motor vehicle occupants before and after implementation of the law. The study period compared all deaths of two wheel motor vehicle occupants from January 1990 to December 1992 (pre-law period) with those from January 1993 to December 1995 (post-law period) detected by the Barcelona Forensic Institute and the city police department. The former provided autopsy information on cause of

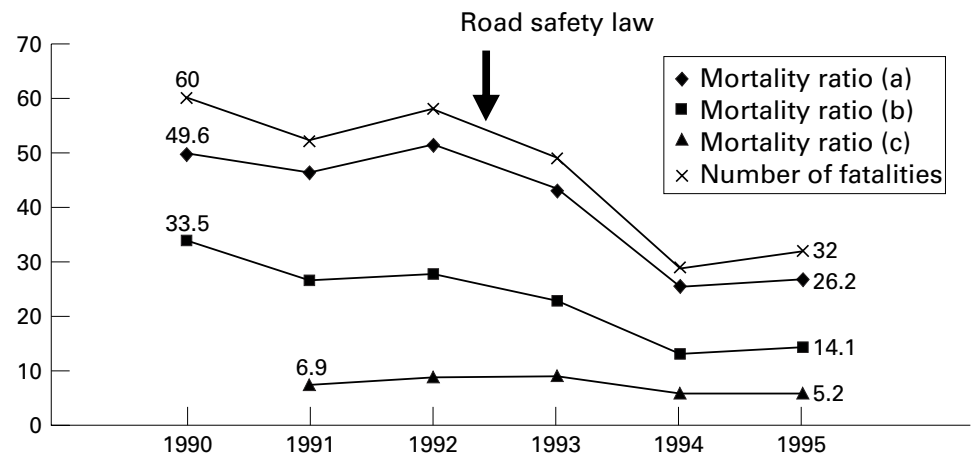

Figure 1 Mortality trends among two wheel vehicle users, Barcelona, 1990-95. Mortality ratio $(a)=\times 10^{7}$ vehicle $\mathrm{km} ;(\mathrm{b})=\times 10^{5}$ two wheel vehicles; $(C)=10^{3}$ two wheel crashes.

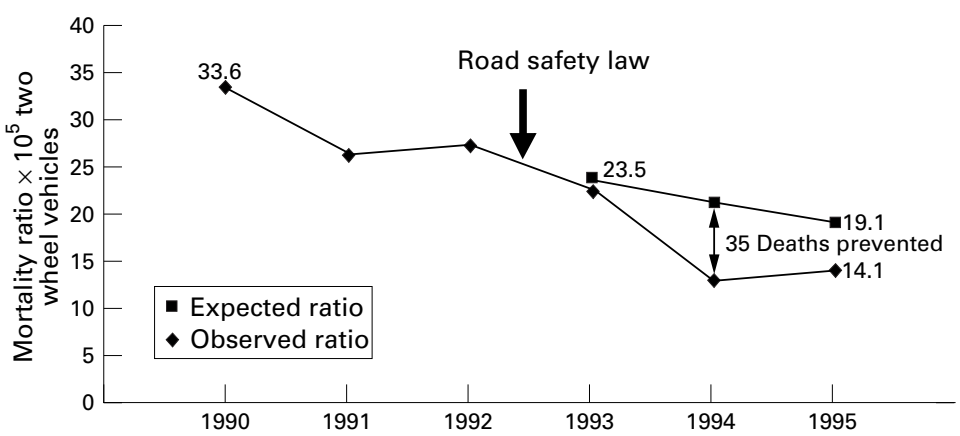

Figure 2 Differences between post-law fatality ratios observed and expected (by a Poisson regression model: $\log$ (ratio) $=1.309-0.1039$ (year)), Barcelona, 1993-95. death and injury description for all deaths of two wheel motor vehicle occupants involved in crashes within the city boundaries. City police records provided information on the circumstances of the crash. Highway police records were also checked to exclude deaths resulting from crashes outside Barcelona. Data on the number of registered vehicles were provided by the city vehicle registry. Data on vehicle kilometres and number of motor vehicle crashes were obtained by the city traffic authority. Finally, data on helmet use were obtained from the Catalan Institute for Highway Safety (L'ús del casc a Catalunya. Barcelona: Institut Català de Seguretat Viària, unpublished data).

The variables considered in the analysis were demographic (age and sex), user position (driver or pillion), and the anatomic location and severity of injury. All injuries were coded by trained personnel using the 1990 version of the abbreviated injury scale (AIS). ${ }^{32}$

Mortality ratios using number of registered two wheel vehicles, vehicle kilometres, and number of two wheel crashes as exposure denominators were computed and $95 \%$ confidence intervals (CI) were calculated according to the exact Poisson distribution Poisson regression methods, ${ }^{33}$ were used to model trends in mortality ratios and to provide estimates of the number of lives saved attributable to the road safety law. More specifically, the model allowed the estimation of the expected mortality ratios for 1993-95 based on the observed trends for the 1990-92 period (pre-law period), and then allowing for the calculation of the difference between the number of observed and expected deaths for the 1993-95 period (post-law period). Statistical analyses were performed using the SPSS software package. ${ }^{34}$

\section{Results}

The total number of motorcycle and moped occupant deaths during the study period was 280 . Most of these deaths involved men $(85 \%)$, motorcycle drivers ( $85 \%$ ), and young riders: 25 years (SD 12.4), without any significant differences between the pre-law and the post-law period (table 1).

The number of fatalities decreased from 60 in 1990 to 32 in 1995. Mortality (95\% CI) decreased annually, from 49.6 (37.9 to 63.8) deaths/10 000000 two wheel kilometres in 1990 to 26.2 (17.9 to 37) in 1995 (fig 1 ). Mortality also decreased, from 33.5 (25.6 to 43.2 ) deaths/100 000 registered motorcycles in 1990 to 14.1 (9.7 to 19.9 ) in 1995 . When crashes were taken into account, mortality declined, from 6.9 (5.2 to 9.1) to 5.2 (3.6 to 7.4 ) deaths/ 1000 reported two wheel motor vehicle crashes. Although the inflection of the frequency distribution began in 1993, after the implementation of the law, it did not become statistically significant until 1994 .

The Poisson regression model, using mortality ratios per number of registered vehicles, showed that between 1993 and 1995, 35 lives of motorcycle occupants were spared. This is a 
Table 2 Head injury severity and anatomical region with most severe injury in two wheel vehicle user deaths (Barcelona 1990-95); results are number (\%)

\begin{tabular}{lll}
\hline & $\begin{array}{l}\text { Pre-law } \\
(1990-92)\end{array}$ & $\begin{array}{l}\text { Post-law } \\
(1993-95)\end{array}$ \\
\hline Head injury severity & & \\
MAIS $=0-2$ & $13(8.1)$ & $18(17.3)$ \\
MAIS $=3-4$ & $122(76.3)$ & $70(67.3)$ \\
MAIS =5-6 & $25(15.6)$ & $16(15.4)$ \\
Total & $160(100)$ & $104(100)$ \\
Mean MAIS & 3.7 & 3.7 \\
Anatomical region with most severe injury & \\
Head & $117(73.5)$ & $58(55.8)$ \\
Chest & $26(16.7)$ & $33(31.7)$ \\
Abdomen & $9(5.6)$ & $12(11.5)$ \\
Other & $8(4.2)$ & $0(0)$ \\
Total & $160(100)$ & $104(100)$ \\
Mean injury severity score & 25.8 & 31.3 \\
\hline
\end{tabular}

${ }^{\star} \mathrm{p}<0.01 ;{ }^{\star \star}$ non-significant; ${ }^{\star \star \star} \mathrm{p}<0.05$

Neck, face, upper and lower extremities, spine, external are not shown due to lack of cases in those categories.

total decrease of $25 \%$ in the observed motorcycle crash mortality in the three year period after helmet law implementation compared with what would be expected if no such law had gone into effect (fig 2).

The proportion of motorcycle deaths showing no injuries or low severity injuries (maximum AIS (MAIS) $\leqslant 2$ ) to the head increased from $8.1 \%$ in the pre-law period to $17.3 \%$ in the post-law period. Similarly, the proportion of deaths with severe head injuries (MAIS = 3-4) was reduced from $76 \%$ to $67 \%$ in the post-law period (table 2). The distribution of injuries by anatomic region also changed in both periods, with a $24 \%$ post-law decrease in the proportion of deaths in which the head was the region most severely injured. In the post-law period, however, other regions, such as the thorax, had a higher contribution to the most severe injuries. Mean injury severity score was higher in the pre-law period (25.8) than in the post-law period (31.3) (table 2).

Expectedly, and as a consequence of the reduction in the number of two wheel motor vehicle occupants dying as a result of a head

Table 3 Most severely injuries to anatomic regions in two wheel vehicle use deaths; results are number (\%)

\begin{tabular}{llllll}
\hline \multirow{2}{*}{ Anatomical region * } & \multicolumn{2}{l}{ Pre-law (1990-92) } & & \multicolumn{2}{l}{ Post-law (1993-95) } \\
\cline { 2 - 3 } & Total injuries & AIS $\geqslant 4$ & & Total injuries & AIS $\geqslant 4$ \\
\hline Head & $392(100)$ & $109(27.8)$ & & $239(100)$ & $59(24.7)$ \\
Chest & $167(100)$ & $62(37.1)$ & & $186(100)$ & $77(41.3)$ \\
Abdomen & $115(100)$ & $35(30.4)$ & & $118(100)$ & $41(34.7)$ \\
\hline
\end{tabular}

${ }^{\star} \mathrm{p}<0.05$.

Neck, upper and lower extremities, and external are not shown due to lack of cases in those categories.

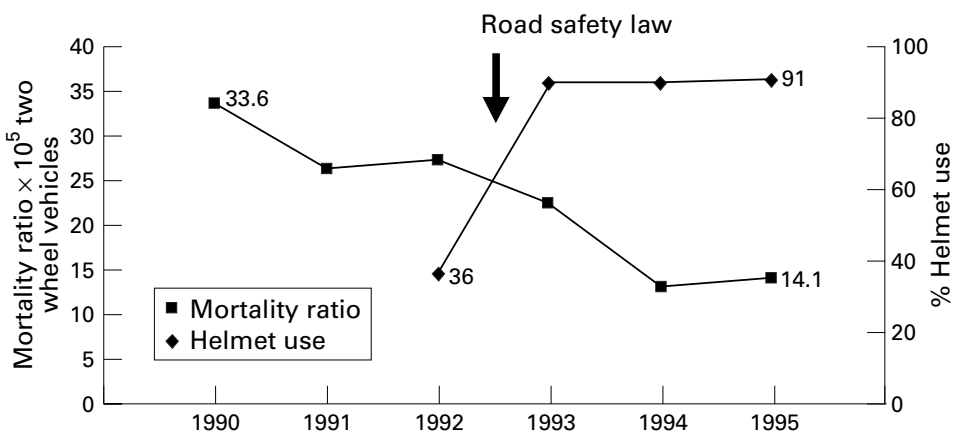

Figure 3 Mortality trends and prevalence of helmet use, Barcelona, 1990-95. injury in the post-law period, there was in increase in proportion of fatal cases with more severe injuries (AIS $\geqslant 4$ ) in anatomical regions other than the head, such as the thorax and the abdomen (table 3 ).

\section{Discussion}

This study offers the first evaluation of a motorcycle helmet law using combined forensic and police data in Barcelona area where motorcycle use is widespread. Our results confirm the effectiveness of the helmet law, as measured by the reduction in the number of deaths and in mortality ratios after law implementation. The fact that mortality per motor vehicle crash decreased less than mortality per vehicle and per vehicle kilometre is due to the fact that the number of crashes involving two wheel motor vehicles in the post-law period increased less than the number of such vehicles as well as the number of vehicle kilometres.

Our study indicates that the introduction of the road safety law was followed by a $25 \%$ reduction in the expected relative mortality among two wheel motor vehicle occupants in the subsequent three year period. Despite difficulties when comparing these results with similar interventions reported for other settings, these results are consistent with what has been observed in the US states where a helmet law has been passed, reductions ranging from $42 \%$ and $66 \%$ in Louisiana, ${ }^{22} 37.5 \%$ in California, ${ }^{19}$ and $12.6 \%$ in Texas. ${ }^{27}$ Conversely, motorcycle crash mortality increased by $40 \%$ as a result of the derogation of the law, ${ }^{28}{ }^{29}$ which was again followed by a new decrease of $38 \%$ in states where the law was reintroduced. ${ }^{26}$ The results are also consistent with a previous study that showed a beneficial effect of the helmet law in Barcelona, ${ }^{30}$ although the assessment was limited to one year after the law's implementation, and did not look at injury distribution and severity.

The results indicate that the helmet law seems also to have contributed to a reduction in head involvement in fatal cases, as indicated by the increase in the proportion of fatalities without any head injuries, as well as the decrease in the proportion of fatalities in which the head was the region with the highest severity. This is consistent with studies reporting that mortality among motorcycle users attributable to head injuries decreased after the introduction of a helmet law. ${ }^{85}$ Similarly, like in Barcelona, other studies have found that the introduction of such a law resulted in a $22 \%$ reduction in severe head injuries (AIS $=3$ ), ${ }^{26}$ a $57 \%$ decrease in emergency department admissions with severe head injuries (AIS $=4$ ), ${ }^{24}$ a $20 \%$ decrease among fatally injured riders with severe head injuries, ${ }^{19}$ and a $34 \%$ reduction in subsequent impairments resulting from a head injury. ${ }^{36}$

The fact that in Barcelona, mortality has been shown to decrease in the post-law period after taking into account exposure (defined either in terms of two wheel motor vehicle kilometres, number of licensed vehicles and number of crashes, together with the lesser 
involvement of head injuries after the law) is consistent with the protective effect of an increase in helmet use by motorcyclists. However, compliance with the law remains a critical issue. Although limited, there is only partial evidence indicating that the motorcycle helmet law in Barcelona was associated with an increase in helmet use. In 1992, before the law, the prevalence of helmet use in the city was about 36\%. It increased to $90 \%$ in 1993 (L'ús del casc a Catalunya. Barcelona: Institut Català de Seguretat Viària, unpublished data) (fig 3). Most studies evaluating the impact of helmet laws have shown a substantial increase in helmet use after its implementation. ${ }^{18}{ }^{23} 26$ The increase is greater when such laws are mandatory $^{28}$ and less when only voluntary. ${ }^{22} 233037$

In the post-law period, other anatomical regions such as the thorax and the abdomen showed a greater relative contribution to more severe injuries. This is similar to what has been reported elsewhere, ${ }^{19}$ although some studies point out that the severity in those regions was similar between those who wore a helmet and those who did not. ${ }^{11} 12$ The importance of more intensive efforts towards the prevention of thoracic and abdominal injuries has been raised by some authors. ${ }^{11}$ In Barcelona, the contribution of spine injuries with a higher severity did not vary substantially after the road safety law. This reinforces the observation that the use of helmets does not increase the risk of spine injuries. ${ }^{5}{ }^{11-13} 172638$

In our study we found that the overall injury severity, as defined by the injury severity score, was higher in post-law than in pre-law deaths. This is likely due to a higher seriousness of the crashes leading to death in the post-law period. Unfortunately, we could not verify this hypothesis since we don't have information about the characteristics of the crashes.

Our results are based on analyses of forensic data, allowing for inclusion of all deaths, because traffic deaths beyond 24 hours after the crash are generally not identified in police records. No data were available on hospitalized motor vehicle injury cases. Social, environmental, or regulatory differences between pre-law and post-law period (other than the helmet use law) may have accounted for a portion of the reduction in fatalities. This might in part explain why the reduction observed was more important in the second year after the law, despite an apparent high use of helmets in the first year. Even so, it is not known whether such high use was homogeneous in the population, or if it took longer to obtain high use levels among subgroups of motorcycle riders at a higher risk of a crash. Moreover, the actual enforcement of the use of helmets complying with European standard regulations did not begin until 1994.

We could not identify any significant changes in legislation, weather conditions, traffic volume, or other factors that would have significantly altered exposure to a crash or subsequent injury. We have observed a greater reduction of crashes in the post-law period in two wheel motor vehicles $(20 \%)$ than in cars
(17\%). This finding reinforces the role of the road safety law in the decrease of traffic crashes in two wheel motor vehicle users. Changes in the criteria for case inclusion, or in the quality of the data recorded throughout the study period did not occur. Thus, the absence of other major environmental events that could potentially explain the observed decrease in mortality supports our conclusion about the benefits of the helmet law in Barcelona.

The findings of this study reinforce the public health benefits of mandatory, non-restricted motorcycle helmet use, even in urban areas with lower traffic speed intensity. Such benefits are even more salient on traffic mortality in areas with a high use of two wheel motor vehicles, as is the case for Barcelona. This underscores the importance of maintaining high levels of helmet use through permanent enforcement and education. Countries in the European Union that still apply restricted helmet laws, such as Italy, Belgium, Germany, and the Netherlands, should seriously reconsider their current policies and extend the compulsory use of helmets to all two wheel motorcycle riders, even in the case of low speed mopeds riding in urban areas.

The authors wish to express their appreciation for the contribution of the following persons to the study data and/or the manuscript preliminary review: X Vilaró and O Comabasosa (Guardia Urbana, Barcelona), F Narvaez and A Ferrer (Ámbit Via Pública, Barcelona), Dra T Tortosa (Institut Anatòmic Forense, Pública, Barcelona), Dra T Tortosa (Institut Anatomic Forense, Barcelona), A Riu (Dirección General de Tráfico), and L
Thorson. This study was supported in part by the Southern Thorson. This study was supported in part by the Southern
California Center for Injury Research and Prevention at the UCLA School of Public Health.

1 World Health Organization. World health statistics annual 1995. Geneva, Switzerland: WHO, 1996.

2 Direccion General de Tráfico. Boletin informativo. Accidentes 1995. Madrid: Dirección General de Tráfico, 1996.

3 Plasència A, Borrell C, Antó JM. Emergency department and hospital admissions and deaths from traffic injuries in Barcelona, Spain. A one-year population-based study. Accid Anal Prev 1995;27:591-600.

4 Ferrando J, Plasència A, MacKenzie E, et al. Disabilities resulting from traffic injuries in Barcelona, Spain: 1-year incidence by age, gender and type of user. Accid Anal Prev 1998;30:723-30.

5 Krantz KPG. Head and neck injuries to motorcycle and moped riders-with special regard to the effects of protecmoped riders-with special regard to
tive helmets. Injury 1985;16:253-8.

6 Kraus JF, Riggins RS, Franti CE. Some epidemiologic features of motorcycle collision injuries. I-Introduction: methods and factors associated with incidence. Am $\mathcal{F}$ Epidemiol 1975;102:74-98.

7 Kraus JF, Riggins RS, Franti CE. Some epidemiologic features of motorcycle collision injuries. II-Factors associated with severity of injuries. Am $\mathcal{F}$ Epidemiol 1975;102:99-109.

8 Sosin DM, Sacks JJ, Holmgreen P. Head injury-associated deaths from motorcycle crashes. $\mathscr{7} A M A$ 1990;264:2395-9.

9 Tsai YJ, Wang JD, Huang WF. Case-control study of the effectiveness of different types of helmets for the prevention effectiveness of different types of helmets for the prevention of head injuries among motorcycle

10 Shankar BS, Ramzy AI, Soderstrom CA, et al. Helmet use, Shankar BS, Ramzy AI, Soderstrom CA, et al. Helmet use,
patterns of injury, medical outcome, and costs among motorcycle drivers in Maryland. Accid Anal Prev 1992;24: motorcy

11 Sarkar S, Peek C, Kraus JF. Fatal injuries in motorcycle riders according to helmet use. $\mathcal{F}$ Trauma 1995;38:242-5.

12 Rowland J, Rivara F, Salzberg P, et al. Motorcycle helmet use and injury outcome and hospitalization costs from crashes in Washington State. Am F Public Health 1996;86: $41-5$.

13 Johnson RM, McCarthy MC, Miller SF, et al. Craniofacial trauma in injured motorcyclists: the impact of helmet usage. F Trauma 1995;38:876-8.

14 Offner PJ, Rivara FP, Maier RV. The impact of motorcycle helmet use. F Trauma 1992;32:636-42.

15 Orsay E, Holden JA, Williams J, et al. Motorcycle trauma in the state of illinois: analysis of the Illinois Department of Public Health Trauma Registry. Ann Emerg Med 1995;26: 455-60.

16 Nelson D, Sklar D, Skipper B, et al. Motorcycle fatalities in New Mexico: the association of helmet nonuse with alcohol intoxication. Ann Emerg Med 1992;21:279-83. 
17 Kelly P, Sanson T, Strange G, et al. A prospective study of the impact of helmet usage on motorcycle trauma. Ann Emerg Med 1991;20:852-6.

18 Kraus JF, Peek C, Williams A. Compliance with the 1992 California motorcycle helmet use law. Am f Public Health 1995;85:96-9.

19 Kraus JF, Peek C, McArthur DL, et al. The effect of the 1992 California motorcycle helmet use law on motorcycle crash fatalities and injuries. $\mathcal{F} A M A$ 1994;272:1506-11.

20 Rutledge R, Stutts J. The association of helmet use with the outcome of motorcycle crash injury when controlling for crash/injury severity. Accid Anal Prev 1993;25:347-53.

21 Braddock M, Schwartz R, Lapidus G, et al. A populationbased study of motorcycle injury and costs. Ann Emerg Med 1992;21:273-8.

22 McSwain NE, Belles A. Motorcycle helmets-medical costs and the law. F Trauma 1990;30:1189-99.

23 Muller A. Evaluation of the costs and benefits of motorcycle helmet laws. Am f Public Health 1980;70:586-92.

24 Mock CN, Maier RV, Boyle E, et al. Injury prevention strategies to promote helmet use decrease severe head injustrategies to promote helmet use decrease severe head inju-

25 Kraus JF, Peek C. The impact of two related prevention strategies on head injury reduction among nonfatally injured motorcycle riders, California, 1991-1993. F Neurotrauma 1995;12:873-81.

26 Muelleman RL, Mlinek EJ, Collicott PE. Motorcycle crash injuries and costs: effect of a reenacted comprehensive helmet use law. Ann Emerg Med 1992; 21:266-72.

27 Fleming NS, Becker ER. The impact of the Texas 1989 motorcycle helmet law on total and head-related fatalities, severe injuries and overall injuries. Med Care 1992;30:83245 .
28 Watson GS, Zador PL, Wilks A. The repeal of helmet use laws and increased motorcyclist mortality in the United States, 1975-1978. Am f Public Health 1980;70:579-85.

29 McSwain NE, Petrucelli E. Medical consequences of motorcycle helmet nonusage. F Trauma 1984;24:233-6.

30 Ballart X, Riba C. Impact of legislation requiring moped and motorbike riders to wear helmets. Evaluation and Program Planning 1995;18:311-20.

31 Kleinbaum DG, Kupper LL, Morgensten H. Epidemiologic research. Principles and quantitative methods. New York: Van Nostrand Reinhold Company Inc, 1982.

32 Association for the Advancement of Automotive Medicine. The abbreviated injury scale. 1990 Revision. Des Plaines, IL: AAAM, 1990.

33 Breslow NE, Day NE. Statistical methods in cancer research. Volume II. The design and analysis of cohort studies. Lyon: International Agency for Research on studies. Lyon:

34 Norusis MJ/SPSS Inc. SPSS for Windows. Base system user's guide. Release 6.0. Chicago: SPSS Inc, 1993.

35 Sosin DM, Sacks JJ. Motorcycle helmet-use laws and head injury prevention. FAMA 1992;267:1649-51.

36 Peek-Asa C, Kraus JF. Estimates of injury impairment after acute traumatic injury in motorcycle crashes before and after passage of a mandatory helmet use law. Ann Emerg after passage of a man $1997 ; 9: 630-6$.

37 Lowenstein SR, Koziol-McLain J, Glazner J. The Colorado motorcycle safety survey: public attitudes and beliefs. $\mathcal{F}$ Trauma 1997;42:1124-8

38 Meyer RD, Daniel WW. The biomechanics of helmets and helmet removal. F Trauma 1985;25:329-32.

\section{More from the journals}

A letter by John Lott of the Yale University School of Law appeared in the March 1 issue of $\mathcal{F} A M A$ criticizing a paper by Wintemute on firearm violence prevention. Lott claims that Wintemute's description of the research on laws regarding concealed handguns and other gun laws is inaccurate. $\mathrm{He}$ asserts that 14 studies have found that concealed handgun laws do not reduce violent crime and that no national study has found a significant adverse effect of right to carry arms. The letter concludes that state waiting periods either increase violent crime or have no effect ( $\mathcal{A} A M A 2000 ; 283: 1137)$.

In a paper published in the $B M \mathcal{F}$, a team under the direction of Ian Roberts concludes that of 279 randomized controlled trials involving head injuries, most are seriously flawed because they are "too small and poorly designed to detect or refute reliably moderate but clinically important benefits or hazards of treatment". The authors add that "Limited funding for injury research and unfamiliarity with issues of consent may have been important obstacles" (BMF 2000;320:1308-11).

Editors note: I strongly suspect that the same finding would apply to most other injury related topics, and probably most trials in other areas as well. Insufficient power is a prevalent failing in all too many studies.

In the US pedestrian fatalities are 36 times higher, and bicycling fatalities 11 times higher, than those of car occupant fatalities per km traveled. But the Netherlands and Germany have much lower fatality rates; pedestrian fatalities per billion $\mathrm{km}$ walked are less than a 10th as high, and bicyclist fatalities are only a quarter as high, as in the US. Over the past two decades the Netherlands and Germany have undertaken a wide range of measures to improve safety: better facilities for walking and bicycling; urban design sensitive to the needs of nonmotorists; traffic calming of residential neighborhoods; restrictions on motor vehicle use in cities; rigorous traffic education of both motorists and non-motorists; and strict enforcement of traffic regulations protecting pedestrians and bicyclists.

Editors note: I found this while browsing the Listserver, Pednet. I was surprised because I had assumed that the strong pedestrian safety movement in the US would have achieved better results than what I have seen in much of Europe. This, and other equally valuable material related to pedestrian safety, can be found at the Victoria Transport Policy Institute web site: www.vtpi.org. Tod Litman is the genius behind this initiative (Pucher J, Dijkstra L, Making walking and cycling safer: lessons from Europe. Transportation Quarterly 2000;54(3)). 